\title{
O atendimento educacional especializado no Brasil (2003-2014)
}

\section{The Specialized Educational Service in Brazil (2003-2014)}

\author{
Andressa Santos Rebelo ${ }^{1}$ \\ andressarbl@gmail.com
}

\begin{abstract}
Resumo
Neste texto, objetivamos discutir parte da relação entre os setores "público" e "privado" na Educação Especial no Brasil, no âmbito do Atendimento Educacional Especializado. Para tanto, analisamos documentos educacionais em diálogo com a literatura pertinente. Vimos que, ao abrir sua disposição para a "Educação Especial", o Decreto $n^{\circ} 7.611 / 2011$ demonstra que a relação entre o poder público e as instituições privadas sem fins lucrativos ainda está viva, independentemente dos esforços empreendidos pelo governo nos últimos anos, das mobilizações de grupos acadêmicos específicos a ela contrários e dos movimentos educacionais e da sociedade organizada ocorridos antes mesmo da promulgação da Constituição Federal.
\end{abstract}

Palavras-chave: Educação Especial, Atendimento Educacional Especializado, Políticas educacionais, Inclusão escolar

\begin{abstract}
This paper aims to discuss part of the relationship between "public" and "private" sectors in Special Education in Brazil within the Specialized Educational Service. Therefore, we have analyzed educational documents in dialogue with the relevant literature. We have seen that the moment when the Decree $n^{\circ} 7.611 / 2011$ opened the "Special Education" provision, it demonstrates that the relationship between the government and private non-profit institutions is still alive, regardless of the efforts made by the government in recent years, the mobilization of specific academic groups against it, and educational movements and organized society which took place before the enactment of the Federal Constitution.
\end{abstract}

Keywords: Special Education, Specialized Educational Service, Educational policies, School inclusion

Ao logo do tempo, o conceito de "atendimento especializado" passou por inúmeras transformações nos documentos educacionais brasileiros. Referimo-nos a essas transformações como "transmutação" por considerar esse termo menos ambíguo do que o de "evolução". A expressão "evolução" transmite a ideia de

\footnotetext{
${ }^{1}$ Doutoranda em educação pela Universidade Federal de Mato Grosso do Sul. Docente da Universidade Federal de Mato Grosso do Sul/Campus do Pantanal, Corumbá-MS.
}

Revista Educação Online, n. 20, set-dez 2015, p. 62-78 
desenvolvimento linear, de processo destinado ao progresso, o que sabemos não corresponder necessariamente à realidade. Discutindo sobre a pertinência dos conceitos de evolução (progresso) e devir na história, política e filosofia na primeira metade do século XX, Gramsci (1987, p. 45) apontava para a pouca expectativa com relação ao progresso social:

[...] não no sentido de que se tenha perdido a fé na possibilidade de dominar racionalmente a natureza e o acaso, mas no sentido "democrático"; ou seja, o de que os "portadores" oficiais do progresso tornaram-se incapazes desse domínio, já que suscitaram forças destruidoras atuais tão perigosas e angustiantes quanto as do passado, tais como as "crises", o desemprego etc.

Para Gramsci (1987), na concepção de devir, procurou-se salvar o que de mais concreto existe no "progresso", a saber, o movimento. Enquanto o movimento é dialético, o progresso está ligado à concepção vulgar de evolução. Assim, falamos em "transmutação", já que o devir não coincide necessariamente com progresso, pois, dialético, nos permite (ante)ver na história tanto avanços quanto retrocessos.

É preciso destacar que abordamos leis que já foram instituídas/regulamentadas, e, desse modo, a natureza de nossa discussão se distingue da que se estabeleceu no momento de sua elaboração. As leis não são transparentes e, mesmo após aprovadas, continuam no campo da disputa em sua implementação e julgamento. Cury (1998, p. 2) afirma que a lei tem um caráter fático, devendo ser cumprida. Assim, ao analisamos a política educacional, não se pode nem assumir uma perspectiva de completa adesão, nem uma iconoclastia, como se ela pudesse não ser seguida:

Uma lei, quando discutida, põe em campo um embate de forças e traz, portanto, consigo uma série de expectativas e até mesmo de esperanças válidas para todos os sujeitos interessados. Se aprovada, gera adesão imediata nos que apostaram em tais expectativas. Para os que não apostaram nessas, resta o caminho de uma crítica que se ofereça como alternativa criadora sob a qual está posta a possibilidade de uma mudança para o futuro a partir do presente. Em ambos os casos, o caminho, por sinal íngreme, se inicia com o estudo minucioso do (inter)texto da lei. Uma lei, quando aprovada, tem um "poder fático". Ela é um fato que se impõe, pela democracia representativa, em um Estado democrático de direito. Nessa medida, ela institui-se como um campo de referência, de significação e de obrigação. Instala-se, então, um processo ascético para quem teve suas expectativas frustradas. Para esses, a imperatividade da lei se impõe como conformidade crítica. Há uma diferença substancial entre conformar-se e oferecer adesão. $\mathrm{Na}$ adesão, o sujeito e o objeto interagem, por assim dizer, no mesmo diapasão. Já a conformidade crítica, diferentemente de uma postura imobilista ou iconoclasta, exige, entre outras coisas, uma comunhão menor entre o sujeito e o objeto. Pela imperatividade legal, o sujeito se conforma dentro das regras do jogo democrático, mas, pela criticidade, ele se 
distancia para ver o objeto em planos diferentes. Como regra, a conformidade crítica, superando maniqueísmos, leva a sério o corpo da lei, distinguindo seus pontos virtuosos e viciosos. A lei torna-se um desafio (grifos do autor).

A conformidade crítica requer, de quem analisa a legislação, o reconhecimento de que sua leitura não é a única possível, mesmo dentro do referencial escolhido, pois os sentidos são determinados pela posição no processo sócio-histórico em que são produzidos e interpretados. A partir desse entendimento, especificamente neste texto, objetivamos, por meio de pesquisa documental, discutir parte da relação entre os setores "público" e "privado" na Educação Especial, no Brasil, no que diz respeito ao Atendimento Educacional Especializado (AEE) entre os anos de 2003 e 2014.

\section{Política de inclusão escolar no Brasil}

No ano de 2003, foi lançado o programa do governo federal "Educação Inclusiva: Direito à Diversidade", entre várias ações que passam a ser desenvolvidas, com a intenção de transformar os sistemas de ensino brasileiros em sistemas de ensino inclusivos. Seus objetivos consistiam em:

a) Geral: - Disseminar a política de construção de sistemas educacionais inclusivos e apoiar o processo de implementação e consolidação do Programa Educação Inclusiva: Direito à Diversidade nos municípios brasileiros. b) Específicos Sensibilizar e envolver a sociedade e a comunidade escolar em particular, na efetivação da política de educação inclusiva. - Formar gestores e educadores para atuar na transformação dos sistemas educacionais em sistemas educacionais inclusivos.(BRASIL, 2005)

A partir desse programa, são articuladas pela Secretaria de Educação Especial (Seesp) ${ }^{2}$ outras ações voltadas ao atendimento das pessoas com deficiência, sobretudo destinadas à educação básica, entre os quais: "Escola Acessível", "Incluir", "Benefício de Prestação Continuada (BPC) na Escola" e o "Programa de Implantação de Salas de Recursos Multifuncionais".

\footnotetext{
2 A Seesp foi extinta pelo Decreto n. 7.480 de 16 de maio de 2011, que "Aprova a Estrutura Regimental e o Quadro Demonstrativo dos Cargos em Comissão do Grupo-Direção e Assessoramento Superiores - DAS e das Funções Gratificadas do Ministério da Educação e dispõe sobre remanejamento de cargos em comissão". A partir de então, as políticas de Educação Especial foram incorporadas pela Secretaria de Educação Continuada, Alfabetização e Diversidade (Secad), que passou a ser denominada Secretaria de Educação Continuada, Alfabetização, Diversidade e Inclusão (Secadi).
}

Revista Educação Online, n. 20, set-dez 2015, p. 62-78 
Entre os anos de 2003 a 2006, o Ministério da Educação apoiou projetos de adequação arquitetônica, propostos pelas secretarias de educação e aprovados pela Seesp, visando à acessibilidade nas escolas. Em 2007, foi criado o programa "Escola Acessível", a fim de adequar o espaço físico das escolas estaduais e municipais e promover a acessibilidade nas redes públicas de ensino.

O programa tem por objetivo promover a acessibilidade e inclusão de alunos com deficiência, transtornos globais do desenvolvimento e altas habilidades/superdotação, matriculados em classes comuns do ensino regular, assegurando-Ihes o direito de compartilharem os espaços comuns de aprendizagem, por meio da acessibilidade ao ambiente físico, aos recursos didáticos e pedagógicos e às comunicações e informações (BRASIL, 2011a). Entre os anos de 2007 a 2008, foram atendidas pelo programa 2.543 escolas $^{3}$.

A partir de 2008, o processo de transferência dos recursos financeiros para acessibilidade passou a ser feito diretamente às unidades executoras das escolas. Em 2010, o programa Escola Acessível passou a atender às escolas públicas de Educação Básica das redes estaduais, municipais e distrital, contempladas no período de 2005 a 2008, pelo Programa de Implantação de Salas de Recursos Multifuncionais, que registraram, no Censo Escolar de 2009, matrículas de estudantes público-alvo da educação especial, nas classes comuns do ensino regular (BRASIL, 2011a).

Já o "Programa de Acessibilidade na Educação Superior" ("Incluir") propõe ações para a garantia do acesso de pessoas com deficiência às instituições federais de ensino superior. O "Incluir" foi criado para fomentar a criação e a consolidação de núcleos de acessibilidade nas instituições federais de ensino superior, organizando ações institucionais para a garantia de integração de pessoas com deficiência à vida acadêmica, visando a eliminar "barreiras comportamentais, pedagógicas, arquitetônicas e de comunicação". O programa lança editais desde o ano de 2005, com a finalidade de apoiar projetos de criação ou reestruturação desses núcleos nas instituições federais de ensino superior ${ }^{4}$. A exceção do programa Incluir, os programas para a educação especial se voltam fundamentalmente à educação básica.

${ }^{3}$ Disponível em: < http://portal.mec.gov.br/> Acesso em: 20 jun. 2015. ${ }^{4}$ Disponível em: <http://portal.mec.gov.br/>. Acesso em: 20 jun. 2015. 
É o caso do "Programa de Acompanhamento e Monitoramento do Acesso e Permanência na Escola das Pessoas com Deficiência, Beneficiárias do Benefício de Prestação Continuada da Assistência Social" (BPC na Escola). De natureza interministerial, foi criado em 2007, sob responsabilidade dos Ministérios da Educação, do Desenvolvimento Social e Combate à Fome, da Saúde e da Secretaria Especial dos Direitos Humanos da Presidência da República (BRASIL, 2009a). Seu objetivo é acompanhar e monitorar o acesso e permanência na escola das pessoas com deficiência, beneficiárias do programa BPC na Escola, na faixa etária de 0 a 18 anos, com a intenção de articular políticas de educação, saúde, assistência social e direitos humanos, a fim de favorecer seu desenvolvimento e participação social (BRASIL, 2009a).

Nessa ação, anualmente, é realizado o pareamento de dados dos beneficiários do BPC com a matrícula no Censo Escolar, para identificar os índices de acesso e de exclusão escolar. O programa se organiza por meio da articulação entre o Grupo Gestor Interministerial, Grupo Gestor Estadual, Grupo Gestor Distrital e Grupo Gestor Local. Em 2008, apontou-se que 71\% dos beneficiários do BPC, com deficiência na faixa de 0 a 18 anos, estavam fora da escola ${ }^{5}$, proporção que, conforme dados do Ministério da Educação, o programa reverteu em 2010. Em 2012, a proporção de beneficiários do BPC fora da escola, nessa faixa etária, era de 29,8\% (BRASIL, 2012).

Em 2007, no mesmo momento em que foram criados os programas "Escola Acessível" e "BPC na Escola", também foi instituído o "Programa de Implantação de Salas de Recursos Multifuncionais", para dar sustentação à política de inclusão escolar. Esse programa passou a ser o responsável pela provisão do Atendimento Educacional Especializado (AEE), no contraturno escolar do aluno público-alvo da Educação Especial. Criado através da Portaria Normativa $n^{\circ} 13$, de 24 de abril de 2007, tem como objetivo principal "apoiar os sistemas públicos de ensino na organização e oferta do atendimento educacional especializado e contribuir para o fortalecimento do processo de inclusão educacional nas classes comuns de ensino" (BRASIL, 2007a, art. $1^{\circ}$, grifo nosso).

5 Disponível em: < http://portal.mec.gov.br/> Acesso em: 20 jun. 2015.

Revista Educação Online, n. 20, set-dez 2015, p. 62-78 
Esses programas foram incorporados ao Plano de Desenvolvimento da Educação (PDE), a fim de serem articulados aos demais programas educacionais. Somente em 2011, eles foram incorporados ao "Plano Viver sem Limite" (BRASIL, 2011b), com o objetivo de articular políticas intersetoriais de atenção integral às pessoas com deficiência, que dizem respeito aos eixos Acesso à Educação, Atenção à saúde, Inclusão social e Acessibilidade.

\section{O Atendimento Educacional Especializado no Brasil}

Nos últimos anos, diversos trabalhos vêm se ocupando em investigar a implementação das políticas de inclusão escolar, em particular as que dizem respeito do Atendimento Educacional Especializado (HASS; BAPTISTA, 2014; JESUS; BAPTISTA; CAIADO, 2011; KASSAR, 2013; MELETTI; BUENO, 2013; PRIETO, 2010). A grande veiculação de pesquisas voltadas a esse aspecto da política diz muito sobre o papel de protagonismo dessa proposta enquanto atendimento especializado às pessoas com deficiência.

Em discussão anterior (REBELO, 2013), destacamos a definição de "atendimento educacional especializado" como, antes de tudo, disposto nas salas de recursos multifuncionais (BRASIL, 2006). Esse atendimento é colocado, não como reprodução de conteúdos programáticos da escola comum, mas como mediador desse processo. No entanto, vemos que deixa de ser apresentada a possibilidade desse atendimento substituir a educação escolar. Embora ressaltando a importância da escolaridade, nos documentos produzidos a partir da década de 1990, até esse momento, a educação especial previa seu funcionamento dentro e fora de escolas comuns, de forma que poderia ter um caráter substitutivo (BRASIL, 2001).

Na Política Nacional de Educação Especial na Perspectiva da Educação Inclusiva (2008), a educação especial é apresentada como modalidade "transversal", articulada ao ensino comum. A educação especial é uma "modalidade de ensino que perpassa todos os níveis, etapas e modalidades, realiza 0 atendimento educacional especializado, disponibiliza os recursos e serviços e orienta quanto a sua utilização no processo de ensino e aprendizagem nas turmas comuns do ensino regular" (BRASIL, 2008a, pp. 9 e 10, grifo nosso). 
A provisão de apoio técnico e financeiro para a implementação do atendimento educacional especializado, preferencialmente na rede pública regular de ensino, foi determinada pelo Decreto $n^{\circ}$ 6.571/2008. Nesse decreto, atendimento educacional especializado é colocado como "conjunto de atividades, recursos de acessibilidade e pedagógicos organizados institucionalmente, prestado de forma complementar ou suplementar à formação dos alunos no ensino regular" (BRASIL, 2008b, art. $1^{\circ}, \S 1^{\circ}$ ). Seu conceito, ao mesmo tempo em que se identifica como apoio ao ensino comum, não é colocado como fazendo parte dele. $O$ "atendimento educacional especializado" deixa de existir de forma substitutiva; as salas de recursos (na forma multifuncional) se estabelecem como lócus dessa configuração de atendimento (KASSAR; REBELO, 2011).

A Resolução CNE/CEB n 4/2009institui as Diretrizes Operacionais para o Atendimento Educacional Especializado na Educação Básica, modalidade Educação Especial, para a implementação do Decreto $n^{\circ}$ 6.571/2008, estabelecendo que "a educação especial se realiza em todos os níveis, etapas e modalidades de ensino, tendo o AEE como parte integrante do processo educacional" (BRASIL, 2009b, art. $\left.3^{\circ}\right)$.

Essa concepção também está presente no Decreto 6.571/2008: o artigo $5^{\circ}$ da Resolução CNE/CEB n4/2009 afirma que o atendimento educacional deve ser realizado, prioritariamente, em sala de recursos multifuncionais da própria escola ou de outra escola, não sendo substitutivo às atividades realizadas nas classes comuns, podendo ser oferecido também por centros de Atendimento Educacional Especializado da rede pública ou de instituições comunitárias, confessionais ou filantrópicas sem fins lucrativos, conveniadas com a Secretaria de Educação ou órgão equivalente dos estados, Distrito Federal ou dos municípios (KASSAR; REBELO, 2011).

As orientações aos municípios para a implementação de serviços através da organização de Centros de Atendimento Educacional Especializado foram dispostas através da Nota Técnica SEESP/GAB/n $/ 2 / 2010$. Ela caracteriza a educação especial como "uma modalidade de ensino transversal aos níveis, etapas e modalidades, que disponibiliza recursos e serviços e realiza 0 atendimento educacional especializado, de forma não substitutiva à escolarização" (BRASIL, 2010a, p. 1, grifos nossos). Há aqui uma tarefa imputada à educação especial: Revista Educação Online, n. 20, set-dez 2015, p. 62-78 
disponibilizar recursos e realizar o modelo proposto de atendimento educacional especializado.

Mais uma vez, utiliza-se como conceito de "atendimento educacional especializado", o conjunto de atividades e recursos pedagógicos e de acessibilidade organizados institucionalmente, prestado de forma complementar ou suplementar à formação dos alunos público-alvo da educação especial, matriculados no ensino regular. O Atendimento Educacional Especializado deve ser ofertado em salas de recursos multifuncionais ou em Centros de Atendimento Educacional Especializado (BRASIL, 2010a, pp. 1 e 2). A Nota Técnica SEESP/GAB/n¹1/2010, que traz as "orientações para a institucionalização da Oferta do Atendimento Educacional Especializado - AEE em Salas de Recursos Multifuncionais, implantadas nas escolas regulares", mantém o conceito de educação especial e atendimento especializado anterior (BRASIL, 2010b).

Ao final de 2011, foi aprovado o Decreto $n^{\circ} 7.611 / 2011$, que "dispõe sobre a educação especial, o atendimento educacional especializado e dá outras providências", revogando então o Decreto n 6.571/2008. No Decreto 7.611/2011, o governo especifica alguns aspectos relacionados ao "atendimento educacional especializado", sobretudo no que diz respeito à matrícula dupla e ao consequente recurso duplo oriundo do Fundo de Manutenção e Desenvolvimento da Educação Básica e de Valorização dos Profissionais da Educação (Fundeb). Segundo esse decreto, o AEE deveria ser prestado de modo: "I - complementar à formação dos estudantes com deficiência, transtornos globais do desenvolvimento, como apoio permanente e limitado no tempo e na frequência dos estudantes às salas de recursos multifuncionais; ou II - suplementar à formação de estudantes com altas habilidades ou superdotação" (BRASIL, 2011c, art. $2^{\circ}$, grifos nossos).

Nas leis complementares instituídas nas duas últimas gestões do governo federal (2003-2006; 2007-2010), transparece a tentativa de, mesmo que sutilmente, desconsiderar as ações da gestão anterior na área da educação especial. Isso é perceptível pelo trecho do Parecer CNE/CEB n 13/2009, no qual se afirma:

Em janeiro de 2008, a nova "Política Nacional de Educação Especial na perspectiva da educação inclusiva" da SEESP/MEC é publicada, passando a orientar os sistemas educacionais para a organização dos serviços e recursos da Educação Especial de forma complementar ao ensino regular, como oferta obrigatória e de responsabilidade dos sistemas de ensino. Essa Política resgata o sentido da Educação Especial expresso na Constituição Federal de 1988, que interpreta esta 
modalidade não substitutiva da escolarização comum e define a oferta do atendimento educacional especializado - AEE em todas as etapas, níveis e modalidades, preferencialmente no atendimento à rede pública de ensino (BRASIL, 2009c, p. 1).

No trecho acima, há um salto temporal entre a Constituição Federal de 1988 e a Política Nacional de Educação Especial na Perspectiva da Educação Inclusiva (2008). Apesar do Parecer $n^{\circ} 13$ fazer menção à Ldben/96, silencia-se em relação ao Parecer CNE/CEB n 17/2001 e a Resolução CNE/CEB n²/2001, o que nos chama atenção, devido à relevância de ambos os documentos para a história da educação especial no Brasil. Tal desconsideração nos leva a ponderar que, apesar de a política de inclusão escolar no país se constituir como política de Estado (caracterizada por princípios que ultrapassam os diferentes governos), enquanto política de governo (caracterizada por princípios distintos, conforme as alianças políticas em questão), o último deles procura enfatizar a existência de diferenças, mesmo que questionáveis, em sua condução.

\section{As matrículas de Atendimento Educacional Especializado em disputa}

A movimentação política das instituições especializadas por recursos públicos vem ocorrendo desde a disposição da Lei do Fundo de Manutenção e Desenvolvimento do Ensino Fundamental e de Valorização do Magistério (Fundef) (Lei $n^{\circ}$ 9.424/96), ainda durante o governo de Fernando Henrique Cardoso. Tal situação se reproduziu quando da promulgação da Lei que regulamentou o Fundeb.

Essa mobilização ocorreu no período em que foi promulgado o Decreto $n^{\circ}$ 6.253/2007, de 13 de novembro de 2007, que regulamentava a "Lei do Fundeb" (Lei $\mathrm{n}^{\circ}$ 11.494, de 20 de junho de 2007) e tratava sobre a alocação de recursos para o "Programa de Implantação de Salas de Recursos Multifuncionais", a fim de garantir que esse fundo também provesse o Atendimento Educacional Especializado disseminado pelo programa. No artigo 14 desse Decreto, dizia-se que seriam computadas apenas as "matrículas efetivadas em atendimento educacional especializado complementar à escolarização dos alunos com deficiência, matriculados na rede pública regular de 
ensino, em observância ao disposto no parágrafo único do art. 60 da Lei $n^{\circ}$ 9.394, de 1996”6 (BRASIL, 2007b, art. 14, § 1ํ, grifo nosso).

Cerca de duas semanas depois, o Executivo Federal cedeu às pressões feitas por instituições especializadas, alterando o Decreto $n^{\circ} 6.253 / 2007$, por meio do Decreto $n^{\circ}$ 6.278/2007, de 29 de novembro de 2007 (BRASIL, 2007c). Esse último revogou o artigo 14 do Decreto $n^{\circ}$ 6.253/2007, para garantir que os recursos do Fundeb também beneficiassem as escolas especiais de caráter assistencial.

Tal mobilização foi, em parte, encerrada, quando o Decreto $n^{\circ}$ 6.571/2008 dispôs que $o$ atendimento educacional especializado poderia ser oferecido pelos sistemas públicos de ensino ou pelas instituições comunitárias, confessionais ou filantrópicas sem fins lucrativos, com atuação exclusiva na educação especial, conveniadas com o poder executivo competente (BRASIL, 2008b, art. $6^{\circ}$ ). A partir de então, as instituições especializadas poderiam se organizar na forma de Centros de Atendimento Educacional Especializado. Assim, o Decreto $n^{\circ} 6.571 / 2008$ dispõe que o Decreto $n^{\circ} 6.253 / 2007$ passava a vigorar acrescido do seguinte artigo:

Art. $6^{\circ}$ Admitir-se-á, a partir de $1^{\circ}$ de janeiro de 2010, para efeito da distribuição dos recursos do FUNDEB, o cômputo das matrículas dos alunos da educação regular da rede pública que recebem atendimento educacional especializado, sem prejuízo do cômputo dessas matrículas na educação básica regular. Parágrafo único. $\mathbf{0}$ atendimento educacional especializado poderá ser oferecido pelos sistemas públicos de ensino ou pelas instituições mencionadas no art. 14. (grifos nossos)

Em relação ao financiamento, a Nota Técnica SEESP/GAB/n 9/2010, que traz orientações aos municípios para a implementação do Atendimento Educacional Especializado, através da organização de Centros de Atendimento Educacional Especializado, afirma que os serviços disponibilizados pelas instituições especializadas não seriam apenas os previstos por essa política, uma vez que os recursos oriundos do Fundeb (que condiciona a matrícula no ensino comum) não provocariam prejuízo dos outros convênios (entre as instituições e o governo) já existentes:

\footnotetext{
6 "Art. 60. Os órgãos normativos dos sistemas de ensino estabelecerão critérios de caracterização das instituições privadas sem fins lucrativos, especializadas e com atuação exclusiva em educação especial, para fins de apoio técnico e financeiro pelo Poder Público. Parágrafo único. O Poder Público adotará, como alternativa preferencial, a ampliação do atendimento aos educandos com necessidades especiais na própria rede pública regular de ensino, independentemente do apoio às instituições previstas neste artigo" (BRASIL, 1996).
}

Revista Educação Online, n. 20, set-dez 2015, p. 62-78 
O convênio entre a instituição especializada e a Secretaria de Educação para a oferta do AEE pode ser efetuada sem prejuízo das parcerias com os demais órgãos públicos responsáveis pelas políticas setoriais de saúde, do trabalho, da assistência, efetivados para a oferta de serviços clínicos, terapêuticos, ocupacionais, recreativos, de geração de renda mínima, entre outros. (BRASIL, 2010a, p. 3)

Em relação aos serviços, coloca-se como atribuição do Centro de AEE "participar das ações intersetoriais realizadas entre a escola comum e os demais serviços públicos de saúde, assistência social, trabalho e outros necessários para o desenvolvimento dos alunos" (BRASIL, 2010a, p. 4). No texto, também se encontra a tentativa de otimizar o processo de implantação do atendimento especializado, aproveitando os recursos já existentes, pois se coloca como atribuição das instituições especializadas que aderirem à proposta

[...] organizar o projeto político pedagógico para o atendimento educacional especializado, tendo como base a formação e a experiência do corpo docente, os recursos e equipamentos específicos, o espaço físico e as condições de acessibilidade, de que dispõe (BRASIL, 2010a, p. 3, grifos nossos).

Aqui não se caracteriza apenas a disputa por alocação de recursos (no setor público ou privado), para o atendimento a essas pessoas, mas se trata de uma declaração explícita, para que se aproveite a rede de atendimento já existente como forma de afirmar a política de inclusão escolar, que pretende (ou pretendia no início) transformar completamente os sistemas de ensino. Configura-se nisso um recuo em favor das instituições especializadas.

Em 2011, o Decreto $n^{\circ} 7.611 / 2011$ (que revogou o Decreto $n^{\circ} 6.571 / 2008$ ) estabeleceu que o artigo $9^{\circ}$-A e o artigo $14\left(\S 1^{\circ}\right.$ e $\left.2^{\circ}\right)$ do Decreto $n^{\circ} 6.253 / 2007$ passavam a vigorar com as seguintes alterações:

Art. 9--A. Para efeito da distribuição dos recursos do FUNDEB, será admitida a dupla matrícula dos estudantes da educação regular da rede pública que recebem atendimento educacional especializado.

§ 1ํ A dupla matrícula implica o cômputo do estudante tanto na educação regular da rede pública, quanto no atendimento educacional especializado.

§ 2o $O$ atendimento educacional especializado aos estudantes da rede pública de ensino regular poderá ser oferecido pelos sistemas públicos de ensino ou por instituições comunitárias, confessionais ou filantrópicas sem fins lucrativos, com atuação exclusiva na educação especial, conveniadas com o Poder Executivo competente, sem prejuízo do disposto no art. 14.

Art. 14. Admitir-se-á, para efeito da distribuição dos recursos do FUNDEB, o cômputo das matrículas efetivadas na educação especial oferecida por instituições comunitárias, confessionais ou filantrópicas sem fins lucrativos, com atuação exclusiva na educação especial, conveniadas com o Poder Executivo competente. 
§1 Serão consideradas, para a educação especial, as matrículas na rede regular de ensino, em classes comuns ou em classes especiais de escolas regulares, e em escolas especiais ou especializadas.

§ 20 O credenciamento perante o órgão competente do sistema de ensino, na forma do art. 10, inciso IV e parágrafo único, e art. 11, inciso IV, da Lei $n^{\circ}$ 9.394, de 1996, depende de aprovação de projeto pedagógico. (BRASIL, 2011c, grifos nossos)

É preciso destacar que o parágrafo primeiro do artigo 14 já estava presente no Decreto $n^{\circ}$ 6.278/2007. Dessa forma, foram garantidos os recursos do Fundeb também às instituições especializadas, independentemente de nelas ser prestado ou não o Atendimento Educacional Especializado, sob a forma do "Programa de Implantação de Salas de Recursos Multifuncionais", não condicionando a matrícula de seu público nas escolas regulares para o recebimento desse financiamento.

Em relação à necessidade de explicitação dos objetivos que guiaram a elaboração do Decreto $\mathrm{n}^{\circ}$ 7.611/2011, para atenuar 0 clima instalado, posteriormente a sua promulgação foi preciso que a Secadi explicasse o seu conteúdo, devido às manifestações e pedidos de esclarecimento encaminhados por gestores de secretarias de educação, professores de instituições de educação superior e representantes dos movimentos sociais (BRASIL, 2011d). A Secadi afirmou que:

[...] o Decreto $n^{\circ} 7.611 / 2011$ não retoma o conceito anterior de educação especial substitutiva à escolarização no ensino regular, mantendo o caráter complementar, suplementar e transversal desta modalidade, ao situá-la no âmbito dos serviços de apoio à escolarização. [...] Nesse sentido, a modalidade de Educação Especial é parte integrante do ensino regular e não se constitui em sistema paralelo de educação. [...] O Decreto no 7.611/2011 não apresenta inovação com relação ao apoio financeiro às instituições privadas filantrópicas que atuam na educação especial, considerando que seus dispositivos transcrevem 0 art. 60 da Lei $n^{\circ}$ 9.394/1996 e o art. 14 do Decreto $\mathrm{n}^{\circ}$ 6.253/2007, que regulamenta a Lei $\mathrm{n}^{\circ}$ 11.494/2007, que institui o Fundo de Manutenção e Desenvolvimento da Educação Básica e de Valorização dos Profissionais da Educação - FUNDEB. Igualmente, essas instituições continuam tendo o financiamento público por meio do Programa Dinheiro Direto na Escola - PDDE e Programa Nacional de Alimentação Escolar PNAE. $O$ apoio financeiro às instituições especializadas mencionadas, referente ao atendimento de pessoas que não estão matriculadas no ensino regular, destina-se, especialmente, àquelas que se encontram fora da faixa etária de escolarização obrigatória, em razão de um processo histórico de exclusão escolar. (BRASIL, 2011d, grifos nossos)

Tendo em vista a mobilização em torno da publicação desse decreto, entendemos que, a partir dele, configura-se um momento decisivo para que, ou se avance, ou se retroceda em relação à provisão efetiva de educação a essas 
pessoas. É nesse contexto de incertezas, que se encontram as políticas educacionais e as urgentes demandas das pessoas com deficiência, que já há tanto aguardam por políticas que realmente sejam capazes de prover reais condições de acesso e equidade no processo educacional.

Após as discussões em torno do Plano Nacional de Educação (2014-2024) (BRASIL, 2014) e na própria Conferência Nacional de Educação (2014), tais embates foram retomados. Nesse sentido, entendemos não existir descompasso entre o que se estabeleceu como meta e o que se propôs como estratégia no Plano, uma vez que as instituições especializadas conseguiram, em termos de discurso, ainda no embate sobre a Lei do Fundeb, um espaço no seio da política de inclusão escolar:

Meta 4: universalizar, para a população de 4 (quatro) a 17 (dezessete) anos com deficiência, transtornos globais do desenvolvimento $e$ altas habilidades ou superdotação, o acesso à educação básica e ao atendimento educacional especializado, preferencialmente na rede regular de ensino, com a garantia de sistema educacional inclusivo, de salas de recursos multifuncionais, classes, escolas ou serviços especializados, públicos ou conveniados.

Estratégias: 4.1) contabilizar, para fins do repasse do Fundo de Manutenção e Desenvolvimento da Educação Básica e de Valorização dos Profissionais da Educação - FUNDEB, as matrículas dos (as) estudantes da educação regular da rede pública que recebam atendimento educacional especializado complementar e suplementar, sem prejuízo do cômputo dessas matrículas na educação básica regular, e as matrículas efetivadas, conforme o censo escolar mais atualizado, na educação especial oferecida em instituições comunitárias, confessionais ou filantrópicas sem fins lucrativos, conveniadas com o poder público e com atuação exclusiva na modalidade, nos termos da Lei no 11.494, de 20 de junho de 2007; [...]. (BRASIL, 2014, grifos nossos)

O movimento pendular entre a predominância dos interesses das instituições especializadas e dos que defendem a inclusão escolar (abrangendo grupos com concepções muito distintas sobre esse processo) vem permeando as leis da educação especial desde a Lei de Diretrizes e Bases da Educação Nacional (1996) e também o embate entre a defesa para que sejam feitos investimentos na educação pública em contraponto aos interesses de instituições especializadas marcou todo o século XX (JANNUZZI; CAIADO, 2013). Diante desse contexto, temos a impressão de que ainda veremos outros capítulos dessa disputa.

Ao abrir sua disposição para a "Educação Especial", o Decreto n 7.611/2011 demonstra que a "parcial simbiose" entre o poder público e as instituições especializadas, descrita pela professora Gilberta Jannuzzi (1997), ainda está viva, 
independentemente dos esforços empreendidos pelo governo nos últimos anos, das mobilizações de grupos acadêmicos específicos a ela contrários e dos movimentos educacionais e da sociedade organizada, ocorridos antes mesmo da promulgação da Constituição Federal. No século XX, essa coexistência se constituiu característica própria dos Estados capitalistas nos países periféricos (BLACKBURN et al, 1999; DRAIBE, 1998; SAVIANI, 2008). Tal tensão é contínua, apesar de se manifestar mais nitidamente em momentos críticos e decisivos, em que se legisla e regulamenta as políticas educacionais, como o que descrevemos anteriormente.

\section{Considerações Finais}

Por um lado, o Atendimento Educacional Especializado (previsto pelos textos normativos nos últimos anos) é apresentado como conquista das pessoas com deficiência, uma vez que se está equipando as escolas regulares para recebê-las. Por outro lado, levado às últimas consequências (ao deixar esses alunos apenas a cargo desse atendimento), pode fazer com que uma grande parcela dessa população não tenha suas especificidades atendidas por completo, pois se pode entender que bastam os serviços serem disponibilizados nessas salas, para que elas tenham pleno desenvolvimento.

As instituições especializadas vêm sendo beneficiadas, no que diz respeito à dupla matrícula do Fundeb, que, inicialmente, pretendia prover os meios para que as escolas regulares recebessem os alunos com deficiência. Embora nos últimos anos tenha havido uma expansão das matrículas de alunos público-alvo da educação especial, na rede regular de ensino (BRASIL, 2014), os dados do Censo Escolar da Educação Básica (MEC/INEP) apontam que 0 Atendimento Educacional Especializado não tem sido disponibilizado para a maioria dessas pessoas. Persistindo, esse quadro poderá não promover a ampliação das matrículas nas escolas comuns (REBELO, 2012). 


\section{Referências bibliográficas}

BLACKBURN, Robin et al. Estado, democracia e alternativa socialista na era neoliberal. In: SADER, Emir; GENTILI, Pablo. (Orgs.). Pós-neoliberalismo II: que Estado para que democracia? 4eed. Petrópolis: Vozes, 1999.p. 131-182.

BRASIL. Censo Escolar da Educação Básica 2013: resumo técnico. Instituto Nacional de Estudos e Pesquisas Educacionais Anísio Teixeira. Brasília: O Instituto, 2014.

. CONSELHO NACIONAL DE EDUCAÇÃO. CÂMARA DE EDUCAÇÃO BÁSICA. Parecer $n^{\circ}$ 13, de 03 de junho de 2009. Brasília, 2009c.

CONSELHO NACIONAL DE EDUCAÇÃO. CÂMARA DE EDUCAÇÃO BÁSICA. Resolução $n^{\circ} 2$, de 11 de setembro de 2001. Diretrizes nacionais para educação especial na educação básica. Brasília, 2001.

CONSELHO NACIONAL DE EDUCAÇÃO. CÂMARA DE EDUCAÇÃO BÁSICA. Resolução $n^{\circ} 4$, de 2 de outubro de 2009. Diretrizes Operacionais para 0 Atendimento Educacional Especializado na Educação Básica, modalidade Educação Especial. Brasília, 2009b.

MEC. Decreto $n^{\circ} 6.253 / 2007$, de 13 de novembro de 2007. Dispõe sobre o Fundo de Manutenção e Desenvolvimento da Educação Básica e de Valorização dos Profissionais da Educação - FUNDEB, regulamenta a Lei no 11.494, de 20 de junho de 2007, e dá outras providências. Brasília, 2007b.

MEC. Decreto $n^{\circ} 6.278 / 2007$, de 29 de novembro de 2007. Altera o Decreto no 6.253, de 13 de novembro de 2007, que dispõe sobre o Fundo de Manutenção e Desenvolvimento da Educação Básica e de Valorização dos Profissionais da Educação - FUNDEB e regulamenta a Lei $n^{\circ}$ 11.494, de 20 de junho de 2007. Brasília, 2007c.

. MEC. INEP. LDBEN $n^{\circ}$ 9.394/96. Estabelece as diretrizes e bases da educação nacional. Brasília, 1996.

. MEC. Portaria Normativa $n^{\circ} 13$, de 24 de abril de 2007, que dispõe sobre a criação do "Programa de Implantação de Salas de Recursos Multifuncionais". Brasília, 2007a.

MEC. SECADI. DPEE. Nota Técnica $n^{\circ}$ 62/2011, de 8 de dezembro de 2011. Orientações aos Sistemas de Ensino sobre o Decreto n 7.611/2011. Brasília, $2011 d$.

MEC. SECADI. Programa Escola Acessível: manual do programa Escola Acessível. Brasília, 2011a.

. MEC. SEESP. BPC na Escola: documento orientador. Brasília, 2009a.

MEC. SEESP. Educação Inclusiva: direito à diversidade. Documento Orientador. Brasília: MEC/SEESP, 2005.

MEC. SEESP. Nota Técnica SEESP/GAB/n 9/2010, de 09 de abril de 2010. Orientações para a Organização de Centros de Atendimento Educacional Especializado. Brasília, 2010a. 
BARSIL. MEC. SEESP. Nota Técnica SEESP/GAB/n $n^{\circ} 11 / 2010$, de 07 de maio de 2010. Orientações para a institucionalização da Oferta do Atendimento Educacional Especializado - AEE em Salas de Recursos Multifuncionais, implantadas nas escolas regulares. Brasília, 2010b.

MEC. SEESP. Política Nacional de Educação Especial na Perspectiva da Educação Inclusiva. Brasília, 2008a.

MEC. SEESP. Sala de recursos multifuncionais: espaço para atendimento educacional especializado. Brasília, 2006.

Presidência da República. Decreto $n^{\circ}$ 6.571, de 17 de setembro de 2008, que dispõe sobre o atendimento educacional especializado, regulamenta o parágrafo único do art. 60 da Lei $n^{\circ}$ 9.394, de 20 de dezembro de 1996 e acrescenta dispositivo ao Decreto $n^{\circ}$ 6.253, de 13 de novembro de 2007. Brasília, 2008b.

Presidência da República. Decreto $n^{\circ} 7.611$, de 17 de novembro de 2011, que dispõe sobre a educação especial, o atendimento educacional especializado e dá outras providências. Brasília, 2011c.

Presidência da República. Decreto $n^{\circ}$ 7.612, de 17 de novembro de 2011, institui o Plano Nacional dos Direitos da Pessoa com Deficiência - Plano Viver sem Limite. Brasília, 2011b.

Presidência da República. Lei no 13.005, de 25 de junho de 2014, aprova o Plano Nacional de Educação - PNE e dá outras providências. Brasília, 2014.

Secretaria Nacional de Promoção dos Direitos das Pessoas com Deficiências. Secretaria de Direitos Humanos. Encontro Nacional com novos prefeitos e prefeitas. Brasília, 2012.

CURY, Carlos Roberto Jamil. Lei de Diretrizes e Bases e perspectivas da educação nacional. Revista Brasileira de Educação, n. 8, p. 72-85, mai-ago1998.

DRAIBE, Sônia Miriam. O sistema brasileiro de proteção social: o legado desenvolvimentista e a agenda recente de reformas. Caderno de Pesquisa,n.32, 1998. Disponível em: <www.nepp.unicamp.br/>. Acesso em: 20 ago. 2013.

GRAMSCI, Antônio. Concepção dialética da história. $7^{\text {ạed }}$. Rio de Janeiro: Civilização Brasileira, 1987.

HASS, Clarissa; BAPTISTA, Claudio Roberto. A articulação entre o atendimento educacional especializado e o currículo escolar: identificando premissas e tensões. In: ANPED SUL, X, Florianópolis, outubro, 2014. Anais... Florianópolis: Anped Sul, 2015.

JANNUZZI, Gilberta Sampaio de Martino. As políticas e os espaços para a criança excepcional. In: FREITAS, Marcos Cezar de. (Org.). História social da infância no Brasil. São Paulo: Cortez Editora, 1997. p. 183-224.

; CAIADO, Katia Regina Moreno. APAE: 1954-2011: algumas reflexões. Campinas: Autores Associados, 2013.

JESUS, Denise Meyrelles de; BAPTISTA, Claudio Roberto; CAIADO, Katia Regina Moreno. (Orgs.). Prática pedagógica na educação especial: multiplicidade do atendimento educacional especializado. Araraquara: Junqueira \& Marin, 2013. 
KASSAR, Mônica de Carvalho Magalhães. Uma breve história da educação das pessoas com deficiências no Brasil. In: MELETTI, Silvia Márcia Ferreira; KASSAR, Mônica de Carvalho Magalhães. Escolarização de alunos com deficiências: desafios e possibilidades. Campinas: Mercado de Letras, 2013. p.33-76.

; REBELO, Andressa Santos. O especial

na educação, o atendimento especializado e a educação especial. In: VI SEMINÁRIO NACIONAL DE PESQUISA EM EDUCAÇÃO ESPECIAL, 6a, Nova Almeida, ES, 2011. Prática pedagógica na Educação Especial: multiplicidade do atendimento educacional especializado. Porto Alegre: FCAA, 2011. v. 1. p. 1-17.

MELETTI, Silvia Márcia Ferreira; BUENO, José Geraldo Silveira (Orgs.). Políticas públicas, escolarização de alunos com deficiência e a pesquisa educacional. Araraquara: Junqueira \& Marin, 2013.

PRIETO, Rosângela Gavioli. Políticas de inclusão escolar no Brasil: sobre novos/velhos significados para a educação especial. In: MENDES, E. G. M.; ALMEIDA, M. A. (Orgs.). Das margens ao centro: perspectivas para as políticas e práticas educacionais no contexto da educação especial inclusiva. Araraquara: Junqueira \& Marin, 2010.p. 61-78.

REBELO, Andressa Santos. A transmutação do conceito de atendimento especializado na legislação educacional brasileira (1988-2011). In: REUNIÃO NACIONAL DA ANPED, 36a - Sistema Nacional de Educação e Participação Popular: Desafios para as Políticas Educacionais, Goiânia, 2013.Anais...Goiânia: UFG, 2013. p. 1-15.

Os impactos da política de Atendimento Educacional Especializado: análise dos indicadores educacionais de matrículas de alunos com deficiência. 2012. Dissertação (Mestrado em Educação) - Universidade Federal de Mato Grosso do Sul, UFMS. Corumbá, 2012.

SAVIANI, Dermeval. História das ideias pedagógicas no Brasil. 2ª̣ed. Campinas: Autores Associados, 2008. 